
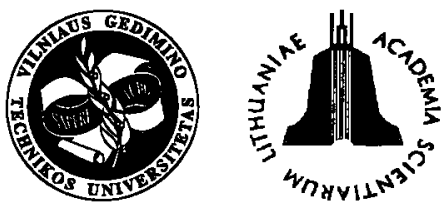

TRANSPORT

http:/www.vtu.lt/english/editions

\title{
THE OPTIMIZATION OF TRANSPORT FLOWS CROSSING LITHUANIAN CUSTOM-HOUSES
}

\author{
A. Jarašūnienè \\ Department of Transport Management, Vilnius Gediminas Technical University (VGTU), \\ Plytinès g. 27, LT-2040 Vilnius, Lithuania,E-mail: aldojara@takas.lt
}

Received 200110 15; accepted 20011219

\begin{abstract}
The importance of the experience of foreign countries, the improvement of the normative and law basis according to improvement standards, the employment of means of information are emphasized in the article.

The investigation of road transport distribution on lines showed that the distribution depends on the flow law of arriving vehicles.

It was proved that the distribution of vehicles according to time and the distribution of vehicles on different lines can be defined by the Erlang law of distribution of the 2 nd sequence.

Keywords: carriers operating, international freight, road carriers, customs work, distribution.
\end{abstract}

\section{Introduction}

The carriers operating in international freight transport by road through the Lithuanian border crossings aim to deliver goods efficiently, effectively and on time. Nevertheless, the unsolved problems in the customs due to inadequately organized work, inefficient or vague laws and rules hinder the common work of carriers and customs officials [1-5].

For this reason first of all financial losses affecting Lithuanian economy are faced.

In the intense process of the reconstruction of the transport system in the Republic of Lithuania, one of the main tasks is to guarantee effective transport activities oriented towards satisfying the needs of Lithuanian economy, especially in international freight transport by road as a priority field.

The investigations carried out on import, export and transit flows in international freight transport by road have shown that freight transport volumes are increasing [6].

In order to guarantee effective international freight transport it is very important to create favourable conditions for it. These conditions are greatly influenced by the custom-house which is an important public institution in charge of performing customs examination and collecting taxes.

Nevertheless Lithuanian customs still do not comply with the requirements adopted in Europe and international transport faces disturbance.

We need to find solutions enabling to attract as much transit freight through Lithuanian customs as possible and to integrate into the system of European Union.

\section{Analysis of relations between road transport carriers and customs officers}

In this article the operations have been put into groups according to the formalized functions and their sequence has been established in compliance with the presented algorithmic block scheme (Fig 1).

Factors belonging to carriers and influencing carrier laws, conventions, instructions, goods turn - over and ecology are defined.

Factors influencing the customs work - the work of customs officers, directing of vehicles in the line, passes, taxes, examination of papers, releasing of vehicles - are described.

The importance of the experience of foreign countries, the improvement of the normative and law basis according to improvement standards and the employment of means of information are emphasized in the article.

\section{Investigation of vehicle flow in time and in separate lines for transport means entering customs territory}

One of the main operations in the customs daily work is the distribution of vehicles in line. This is the connection with the flow of vehicles entering the customs territory. The article describes the distribution of vehicle flow in time and separate lines and gives the investigation of this distribute. The data were calculated using mathematical statistical methods.

Aiming to analyze the flow of vehicles arriving in lines the investigation was carried out on the flow of vehicles arriving in a certain period of time and the distribution of vehicles in lines. The purpose of this investigation 


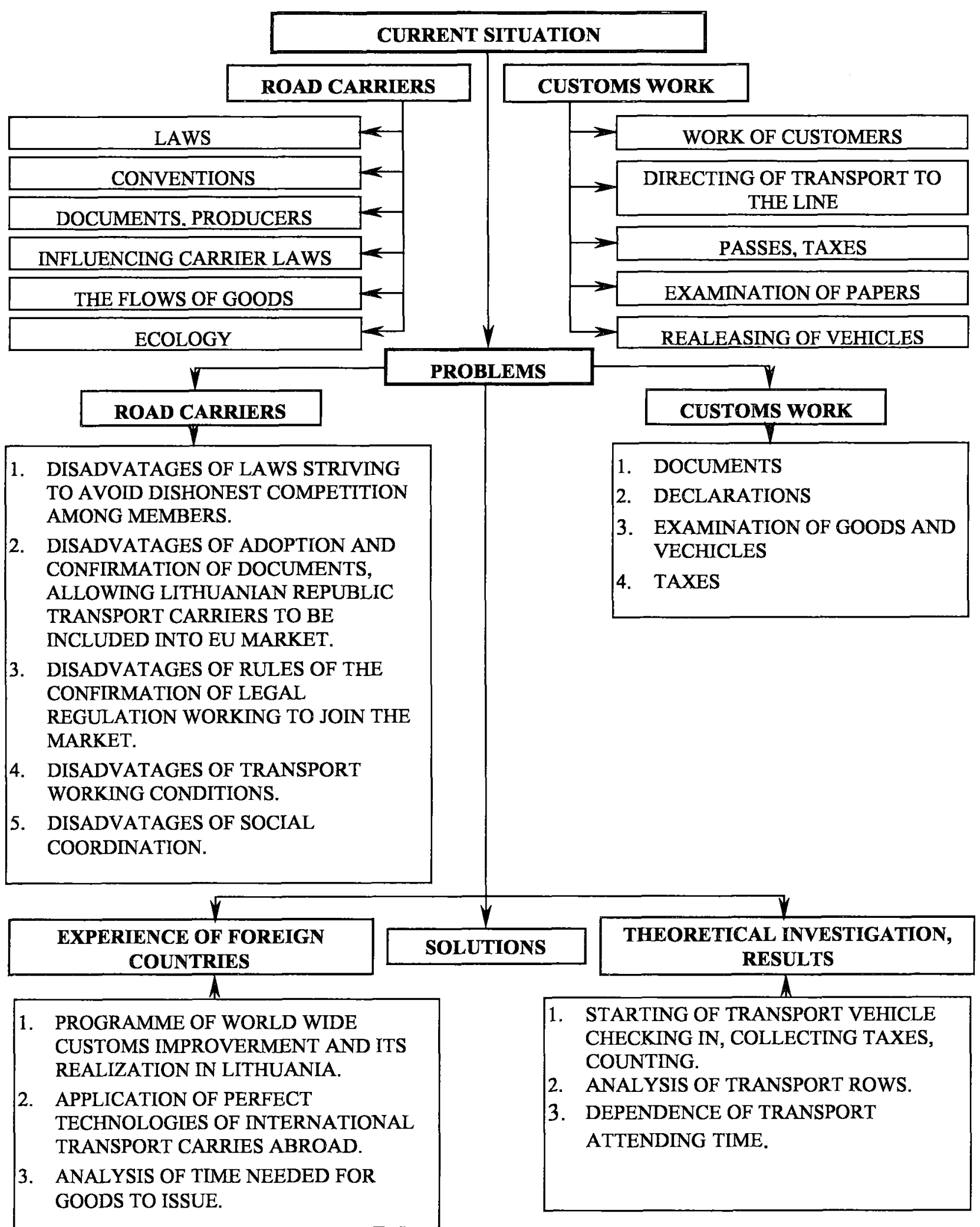

Fig 1. Block scheme of relations between road transport carriers and customs officers 
was the reduction of carriers' idle time at the border crossing points. The investigation lasted for one day from 7 a.m. to 7 p.m. The arrival time of vehicles and their distribution in different lines was fixed. The arrival time of those particular vehicles to the territory of customs was examined.

The data were operated by means of applying methods of mathematical statistics [5].

The approximation of fundamental data applying one of the methods of distribution of theoretical implications is performed in several stages:

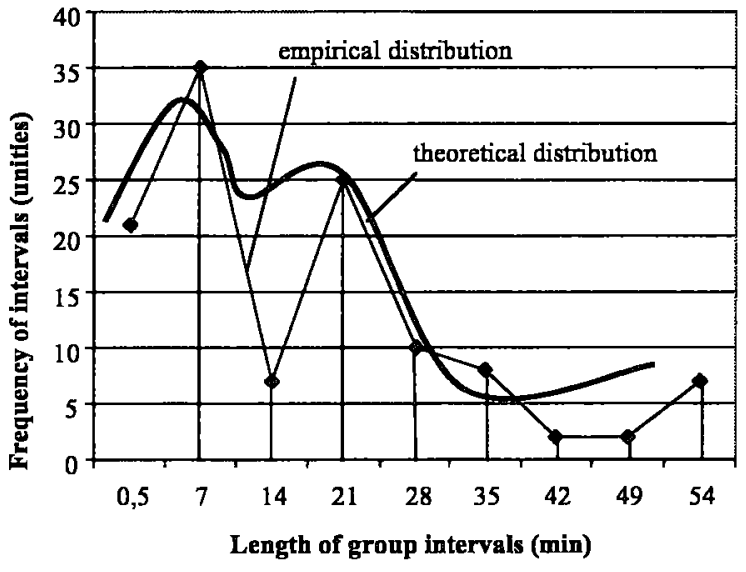

Fig 2. Distribution of intervals among arriving vehicles

The received implications are arranged into groups. The length of the group interval is calculated according to the Stergess formula:

$$
\frac{\Theta_{\max }-\Theta_{\min }}{1+3,32 \lg N},
$$

where $\Theta_{m a x}$ is the maximum time interval, $\Theta_{\min }$ is minimum time interval, $N$ is number of intervals.

The number of measuring which is a component of the group interval is identified by means of calculation.

The data arranged in groups are presented in the Table.

1. The empirical distribution is made and its graphical meaning is compared with the familiar theoretical laws of distribution (Fig 2).

The parallel shows that the empiried distribution resembles the exponential law or the hyperexponential law.

2. The arithmetical mean, dispersion and the standard actual divergence of the data is identified.

The calculations are presented in the Table. A simplified method is applied:

$$
\begin{aligned}
& \bar{\Theta}=\frac{\sum \frac{\Theta_{i}-b}{\Delta \Theta} N_{i} \Delta \Theta+b}{N}, \\
& \sigma_{\Theta}^{2}=\sum_{i} \frac{\left(\frac{\Theta_{i}-b}{\Delta \Theta}\right)^{2}}{N} \cdot(\Delta \Theta)^{2}-(\bar{\Theta}-b)^{2},
\end{aligned}
$$

where $\Theta_{i}-$ is the average of the group interval, $N$ is general measuring number, $N_{l}$ is frequency of intervals, $b$ is

\begin{tabular}{|c|c|c|c|c|c|c|c|c|c|c|}
\hline$Q_{1}$ & 1 & 3,5 & 7 & 10,5 & 14 & 17,5 & 21 & 24,5 & 28 & $\Sigma$ \\
\hline$N_{i}$ & 2 & 22 & 34 & 21 & 9 & 6 & 1 & 1 & 2 & 95 \\
\hline$\frac{Q_{i}-2,5}{l}$ & 3 & 0 & 0,5 & 1 & 1,5 & 2 & 2,5 & 3 & 3,5 & 68,5 \\
\hline$\frac{Q_{1}-2,5}{l} N_{l}$ & 4 & 0 & 11 & 21 & 12 & 12 & 2,5 & 3 & 7 & \\
\hline$\frac{Q_{1}-2,5}{l} N_{i}$ & 5 & 0 & 38,5 & 147 & 126 & 168 & 43,7 & 63 & 171,5 & 757,75 \\
\hline$v k Q_{1}$ & 6 & 11,76 & 23,52 & 35,28 & 47,04 & 58,8 & 70,6 & 82,3 & 94,8 & \\
\hline$p$ & 7 & 0,806 & 0,4282 & 0,6255 & 0,8225 & 0,3190 & 0,3185 & 0,3049 & 0,3032 & \\
\hline$f_{2}\left(Q_{1}\right)$ & 8 & 0,049 & 0,026 & 0,0338 & 0,506 & 0,0196 & 0,005 & 0,0157 & 0,0186 & \\
\hline$\Delta \Theta f_{2}(Q)$ & 9 & 0,005 & 0,003 & 0,0044 & 0,0058 & 0,0022 & 0,0005 & 0,0020 & 0,021 & \\
\hline $\mathrm{Nr}$ & 10 & 32,4 & 17,4 & 24,6 & 33 & 12,6 & 3,6 & 12,6 & 11,4 & 147,6 \\
\hline$\frac{\left(N_{1}-N_{\mathrm{f}}\right)^{2}}{N_{1}}$ & 11 & 0,15 & 1,47 & 0,38 & 16,94 & 3,77 & 2,25 & 11,08 & 7,36 & 45,38 \\
\hline$Q_{I}$ & 12 & 0,39 & 0,77 & 1,16 & 1,54 & 1,93 & 2,31 & 2,69 & 3,08 & \\
\hline$P(1) Q_{1}$ & 13 & 0,3645 & 0,7726 & 0,3183 & 0,3001 & 0,2661 & 0,1958 & 0,1422 & 0,2093 & \\
\hline$f_{2}\left(Q_{1}\right)$ & 14 & 0,040 & 0,0649 & 0,035 & 0,033 & 0,292 & 0,0215 & 0,0156 & 0,0024 & \\
\hline$\Delta Q_{1} f_{2}\left(Q_{1}\right)$ & 15 & 0,0045 & 0,014 & 0,054 & 0,0036 & 0,0033 & 0,0024 & 0,0018 & 0,0002 & \\
\hline$N \boldsymbol{i}$ & 16 & 26,22 & 79,5 & 0,051 & 21,6 & 18,51 & 13,68 & 10,26 & 1,586 & \\
\hline$\frac{\left(N_{t}-N_{n i}\right)}{N i}$ & 17 & 2,31 & 41,87 & 3,04 & 8,56 & 8,72 & 11,75 & 9,35 & 0,11 & 84,68 \\
\hline
\end{tabular}
constant quantity which equals to the average interval, $\sigma$ - dispersion. 
The implications received are mathematical expectancy and evaluation of dispersion in terms of the law of distribution. Since the mathematical expectancy and standard divergence are almost equal, naturally, the law of exponential distribution is chosen for approximation.

4. The empirical distribution is leveled according to the exponential curve.

The law of exponential distribution has four evaluation methods for the parameter $l$ : the quantity which is opposite to the arithmetical mean and which is calculated according to the actual data; graphical method of averages; method of the smallest squares.

The methods of averages and the smallest squares are more exact, lent at the same time they are more complicated. But the experience shows that these methods are not superior if compared with the rest of them, because it is difficult to depict the approximating line graphically exactly within the half-logarithmic netting of co-ordinates. An exceptionally rational evaluation of the exponential distribution parameter is to use the quantity which is opposite to the arithmetical mean.

The expression of the law of exponential distribution is as follows:

$$
\frac{N_{i}}{N} \cong \lambda \mathrm{e}^{-2 \Theta} \Delta \Theta
$$

The act logarithm results in the following:

$$
\lg N_{i}=\lg N+\lg \lambda-\lambda \Theta_{i} \lg e+\lg \Delta \Theta .
$$

After the actual data is inserted, we receive:

$$
\lg N_{\tau i}=3.6423-2.8664 \Theta_{i},
$$

where $N \tau_{I}$ is the theoretical frequency of the interval $i$.

The Table and the diagram show theoretical frequencies of exponential distribution.

The reliability of empirical and theoretical distribution can be verified applying the criterion of conformity which is used in mathematical statistics. The Romanovsky criterion is the most convenient because there is no need to use special tables using it.

According to it empirical and theoretical distribution is accidental, if:

$$
\begin{aligned}
& \frac{\left|x^{2}-\tau\right|}{\sqrt{2 \tau}}<3, \\
& x^{2}=\sum \frac{\left(N_{i}-N_{\tau i}\right)^{2}}{N_{\tau i}},
\end{aligned}
$$

where $\tau$ - is the freedom level cipher equal to the empiric group distribution cipher the connection cipher being excluded within the formation process of theoretical distribution of frequencies.

The law of theoretical distribution is selected in line with statistical data. In the process of verification applying the Romanovsky criterion, an unsatisfactory result is received; nevertheless, taking into account the fact that one third of $x^{2}$ falls under 2 scanty groups, it is feasible to assert that law of approximation used for the identification of the time of arriving vehicles is the Erlang law of distribution.

$$
\begin{aligned}
& f_{k}(\Theta)=\frac{\lambda_{k}^{k} \Theta^{k-1} e^{-\lambda k \Theta}}{(k-1) !}=143(\Theta)^{2} e^{-\lambda \Theta} \\
& f_{k}=143 \Theta^{2} e^{-\lambda \Theta}
\end{aligned}
$$

The investigation of road transport distribution on lines showed that the distribution depends on the flow law of arriving vehicles. It was proved that the distribution of vehicles according to time and the distribution of vehicles on different lines can be defined by the Erlange law of distribution of the 2 nd sequence. The relative density is identified according to the formula.

\section{Conclusions}

1. The importance of the experience of foreign countries, the improvement of the normative and law basis according to improvement standards, the employment of means of information are emphasized in the article.

2. The investigation of road transport distribution on lines showed that the distribution depends on the flow law of arriving vehicles.

It was proved that the distribution of vehicles according to time and the distribution of vehicles on different lines can be defined by the Erlang law of distribution of the 2 nd sequence. The relative density is identified according to the formula:

$$
f_{k}=143 \Theta^{2} e^{-\lambda \Theta} \text {. }
$$

\section{References}

1. Zhan F. Benjamin, Noon Charles E. Shortest Path Algorithms: An Evaluation using Real Road Networks. Transportation Science, Vol 32, No 1, February 1988, p. 65- 73.

2. Powell Warren B., Carvalho Tassio A. Real-Time Optimization of Containers and Flatcars for Intermodal Operations. Transportation Science, Vol 32, No 2, May 1988, p. $110-$ 126.

3. Nuzzolo Agostino, Russo Francesco, Cristalls Umberto. A Doubly Dynamic Schedule - based Assignment Model for Transit Networks. Transportation Science, Vol 35, No 3, 2001, p. 268 - 285.

4. Gattoma D. W. Walters. Managing the Supply Chain. A. Strategic Perspective. Macmillas Press Ltd., 1998. 310 p.

5. Jarašuniene A. Analysis and ways of solving of the Problems of freight transportation by road through the customs of the Republic of Lithuania. Vilnius: Technika, 2000. 240 p.

6. Coule J., Bordi E., Carinato J. Transportation's Third edition. USA, 1999. $525 \mathrm{p}$. 